Article

\title{
Stormwater Field Evaluation and Its Challenges of a Sediment Basin with Skimmer and Baffles at a Highway Construction Site
}

\author{
Xing Fang ${ }^{1, *}$, Wesley C. Zech ${ }^{1}$ and Christopher P. Logan ${ }^{2}$ \\ 1 Department of Civil Engineering, Auburn University, Auburn, AL 36849-5337, USA; \\ E-Mail: zechwes@auburn.edu \\ 2 Turner Construction Company, 5300 Virginia Way, Brentwood, TN 37027, USA; \\ E-Mail: cplogan@tcco.com \\ * Author to whom correspondence should be addressed; E-Mail: xing.fang@auburn.edu; \\ Tel.: +1-334-844-8778; Fax: +1-334-844-6290.
}

Academic Editor: Ataur Rahman

Received: 6 May 2015 / Accepted: 26 June 2015 / Published: 30 June 2015

\begin{abstract}
A field-scale data collection plan to monitor and evaluate the performance of a sediment basin design was developed and implemented using portable automatic stormwater samplers, flow modules, a rain gauge, and inflow weirs. The design configuration consisted of a skimmer as the primary dewatering device, three coir baffles installed inside the basin, polyacrylamide flocculant blocks and ditch checks in the inflow channel. A sediment basin built on a highway construction site in Franklin County, Alabama, U.S. using the aforementioned design configuration was monitored over 16 rainfall events from 15 November 2011 to 6 February 2012. The basin effectively removed sediments during the early stages of construction when the correct type of polyacrylamide flocculant blocks was used, e.g., $97.9 \%$ of sediment removal after a rainfall event on 16 November 2011. It is difficult and challenging to dose sediment-laden stormwater inflow with an exact amount of flocculating agent across all runoff producing events since rainfall is a stochastic variable. Based upon results from this study, it is recommended that a minimum volume of $251.9 \mathrm{~m}^{3} /$ ha of contributing drainage area be used to sufficiently size a basin, which is still significantly under-designed for a 2-year, 24-h storm event in the southeast. This paper presents challenges and lessons learned regarding sediment basin design, monitoring, and performance that are beneficial to future studies.
\end{abstract}


Keywords: best management practice; erosion and sediment transport; sediment basin; stormwater management; runoff control; turbidity; monitoring; construction site

\section{Introduction}

Sediment-laden stormwater runoff from poorly managed construction sites is one of the leading causes of nonpoint source (NPS) pollution in the U.S. and over the world [1]. Construction activities (i.e., land clearing, excavating, and grading) expose bare soil to forces of wind, rain, and stormwater runoff, greatly increasing the potential for erosion. According to the United States Environmental Protection Agency (USEPA), sediment entrained in construction-site stormwater runoff is one of the most widespread pollutants affecting rivers and streams, second only to pathogens [1]. Construction-site sediment yields can be 10 to 20 times greater than those from agricultural lands, and about 1000 to 2000 times greater than those from forested lands [1]. These concerns coupled with growing pressure from regulatory agencies and public scrutiny have resulted in demands to provide enhanced methods for controlling erosion and preventing sediment-laden stormwater discharges from construction sites. Although the USEPA withdrew the federal numeric effluent limitation [2], many state environmental agencies enforce numeric effluent limitations. For example, the Alabama Department of Environmental Management (ADEM) requires effluent turbidity to be less than 50 nephelometric turbidity units (NTU) above background levels for any Alabama waterbody with fish and wildlife designated uses [3]. If stormwater runoff from a construction site violates the effluent limitation, the discharge is prohibited and the construction site operator has to remediate the problem [3].

Various NPS pollution abatement methods and best management practices (BMPs) are commonly used to reduce erosion and sediment transport prior to sediment-laden runoff discharging into a receiving water body. One method of preventing sediment from migrating from construction sites is by capturing it in a sediment basin [4]. Sediment basins provide stormwater detention, promoting gravitational and chemically assisted settling. In this case study, sediment basin monitoring protocols were developed to monitor and evaluate a sediment basin design configuration adopted by the Alabaman Department of Transportation (ALDOT). The sediment basin monitored was constructed on an ALDOT highway construction site in Franklin County, Alabama (AL), U.S. In the past, ALDOT has used a traditional sediment basin design adapted from the 2006 Alabama Handbook [5]. Many traditional sediment basin designs use a $45.7 \mathrm{~cm}$ diameter perforated riser pipe as the primary outlet structure [6]. Routine stormwater inspections following rainfall events have revealed that perforated riser pipes do not allow sediment-laden stormwater to be detained for a sufficient period of time. Furthermore, the riser structure allows basin dewatering to occur across the entire depth of the water column. Following 2009 Alabama Handbook design guidance [7], the ALDOT basin evaluated in this study used a floating surface skimmer as the primary dewatering device with a rip-rap armored emergency spillway to control discharge during extreme rainfall events (Figure 1). The basin design also used three coir baffles positioned inside the basin, polyacrylamide (PAM) application at the inflow channel, as well as an excavated sump, a rip-rap ditch check, and a rip-rap lined inflow channel (Figure 1). The basin design with a skimmer and baffles was based on many years of research performed by the Pennsylvania State University [8-10] and the North 
Carolina State University [11-14], along with experiences of the North Carolina Department of Transportation [15] and other stormwater management agencies in employing these practices on active construction sites.

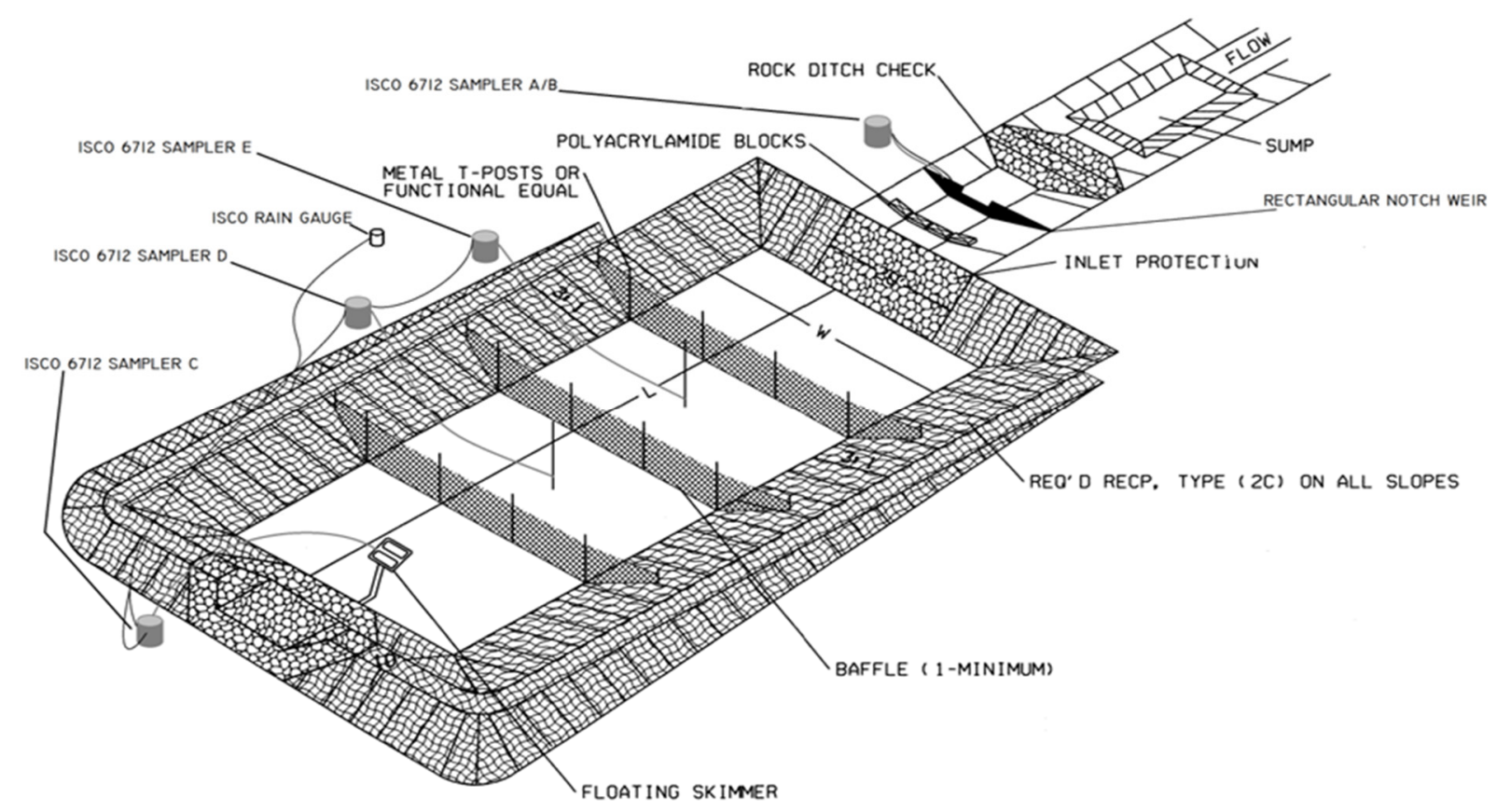

Figure 1. Isometric view of the sediment basin layout including data collection equipment setup.

There are several published field studies on monitoring the performance of sediment basins $[13,16,17]$ and some small- to medium-scale performance-based experimental research studies on sediment basins $[6,8-10,18,19]$. Millen et al. [8] reported that a floating surface skimmer discharged the least total sediment in comparison to four sediment/water control treatments that included a perforated riser in an experimental sediment basin. Bhardwaj and McLaughlin [19] found that both active and passive PAM dosing systems significantly reduced turbidity. McLaughlin et al. [17] reported that basin modifications (e.g., using baffles and a skimmer) have less of an effect on turbidity improvement in comparison to the addition of PAM. The effectiveness of a sediment basin to remove suspended sediments depends on various factors such as: Sediment particle size, ratio of basin surface area to inflow rate [20], sediment properties (e.g., particle density, shape, and concentration), and particle settling velocities. Sediment basins have shown high removal efficiencies for suspended solids, and for heavy metals and organic compounds that have attached to soil particles [21]. Some studies show that a sediment basin can trap more than $75 \%$ of incoming sediments [22]. A more recent study however, showed sediment control systems removed only $35 \%$ to $60 \%$ of incoming sediments from highway construction sites [17]. The removal efficiency of sediment control devices depends on sediment-laden runoff characteristics, which are affected by intensity and duration of storm events, topography and extent of construction limits, soil type and characteristics, vegetative cover composition, and other BMPs implemented upstream [23].

Sediment basins remove suspended solids from stormwater by gravitational settling [24]. A single particle in clear, quiescent water can eventually settle with a constant velocity [25], this is known as the terminal velocity. According to Stokes' Law [26], settling velocity is directly related to particle 
characteristics such as shape factors, specific gravity, and viscosity (function of temperature) [25]. Stormwater runoffs on construction projects often contain very fine suspended sediments that are too small to gravitationally settle under normal conditions. Smaller particles are more susceptible to resuspension due to their position on the basin floor (e.g., last to settle), as well as size and mass [27]. Bhardwaj et al. [28] observed that neither total suspended solids (TSS) nor turbidity was reduced in an open sediment basin (with no baffles) at 1.5-h and 24-h detention times, suggesting that suspended materials were very resistant to settling. It has been determined that clay and silt fractions are the greatest contributors to increased turbidity in runoff [19]. Chemical treatments using coagulants or flocculants, such as PAM, promote the process of suspended sediment bonding to each other to enhance settling. PAM is a high molecular weight synthetic polymer that can be manufactured to have a variety of chain lengths, and to have an anionic, nonionic, or cationic net charge [19]. The preferred form of PAM is the anionic form due to its low aquatic toxicity. Anionic PAM binds to suspended sediment largely through rapid and irreversible cation bridging, pulling particles together into flocs, resulting in an effective chemical flocculant [19].

Zech et al. [29] conducted a survey to determine the state-of-the-practice for sediment basin design, construction, maintenance, and inspection techniques employed by state highway agencies nationwide in the U.S. The survey showed that few agencies actually monitor or collect data from sediment basins. Therefore, performance characteristics for various design configurations of sediment basins remain unknown. There is a lack of information and guidance detailing monitoring protocols for a sediment basin to collect data and analyze the performance of basins. The objective of this paper is to summarize the monitoring data collection plan developed and implemented, along with results of the data analyses performed in a basin constructed on a highway construction site. Even though performance data in a single basin in a unique region may have limitations to be applied to other basins or regions, lessons learned and challenges in monitoring an active sediment basin are also presented. Sharing the experiences (i.e., lessons learned and challenges) and results developed during this study will provide beneficial information to the professional community that may engage in monitoring sediment basin performance. Recommendations were also developed and can be used to enhance the performance of sediment basin designs and implementation. In general, the study is related to monitoring and engineering design of sediment basins used as a sediment control feature for construction stormwater management. The purpose of a sediment basin is to capture suspended solids in an effort to improve the water quality of stormwater runoff and to protect downstream water resources.

\section{Data Collection Plan}

A field-scale data collection plan to monitor and evaluate the performance of a sediment basin was developed and implemented for the case study and consisted of the following elements: (1) rainfall and flow monitoring; (2) stormwater runoff sampling; (3) turbidity and TSS analysis of stormwater runoff samples; (4) soil or stormwater samples to determine particle-size distributions; and (5) a pre and post sediment basin survey to determine the volume of sediment deposited. The data collection plan was adapted and revised from the strategy used for experimental studies of a medium-scale sediment basin at the Sediment and Erosion Control Research and Education Facility in Raleigh, North Carolina [19,28]. Figure 1 illustrates the sediment basin with a single inflow channel along with all necessary structural 
components and sampling equipment used for data collection. The basin design uses a floating surface skimmer as the primary dewatering device, three baffles installed within the basin, and PAM flocculant (floc) blocks placed within the inflow channel (Figure 1). ALDOT design specifications state that baffles shall be constructed of $100 \%$ coconut (coir) fiber materials supported between posts with a wire mesh backing and show that the installed baffle height shall protrude above the spillway crest elevation. The traditional sediment basin design used by ALDOT and many other agencies used a $45.7 \mathrm{~cm}$ diameter, perforated riser pipe as the primary outlet structure $[5,6]$. To monitor water quality in reference to sediment basin performance, five ISCO 6712 (Teledyne Technologies, Inc., Thousand Oaks, CA, USA) full-size portable stormwater samplers, shown in Figure 1, were used to collect stormwater samples at the following locations: Inflow (Sampler A or B), within the sediment basin (Samplers D and E), and outflow (Sampler C).

\subsection{Rainfall and Flow Monitoring}

In an effort to collect rainfall and inflow data, several data collection units were deployed. A tipping bucket rain gauge was connected to Sampler C, shown in Figure 2a,b, to monitor rain events on-site, giving accurate time stamped information regarding rainfall amounts and intensity. Figure $2 \mathrm{~b}$ shows the basin after a rainfall event when both primary and secondary inflow channels were in place. Upstream of the sediment basin, rectangular notched weirs were installed in each channel to gauge inflow into the basin as shown in Figure 1. To properly accommodate inflow from both channels, the rectangular notched weirs were cut to $0.91 \mathrm{~m}$ and $1.22 \mathrm{~m}$ width for secondary and primary inflow channels, respectively, and $0.46 \mathrm{~m}$ in depth. The purpose of these weirs was to provide a means for determining the volume of stormwater inflow entering the basin as well as to conveniently collect inflow water quality samples using the ISCO 6712 samplers.

A 730 bubbler flow module (Teledyne Technologies, Inc., Thousand Oaks, CA, USA) was used to continuously collect necessary data to determine inflow discharges and volumes whenever runoff from the contributing drainage area flowed over the weir. The bubbler flow module was pre-programed and pre-calibrated with the dimension of the rectangular weir, based on the mounting depth below the base of the weir opening, so that as water flowed through the weir it registered a positive water level.

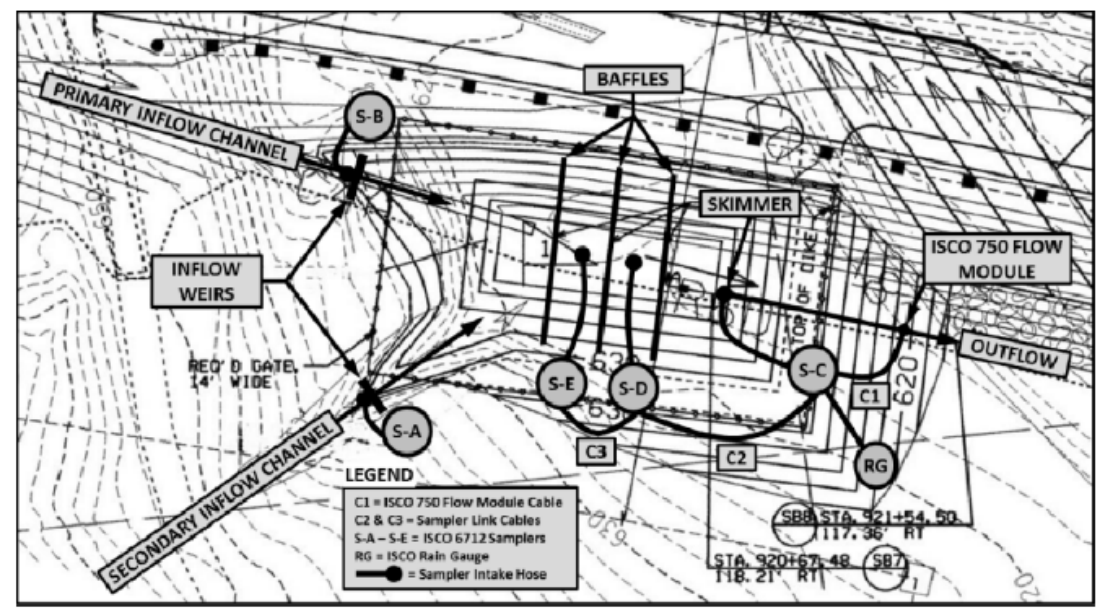

(a)

Figure 2. Cont. 


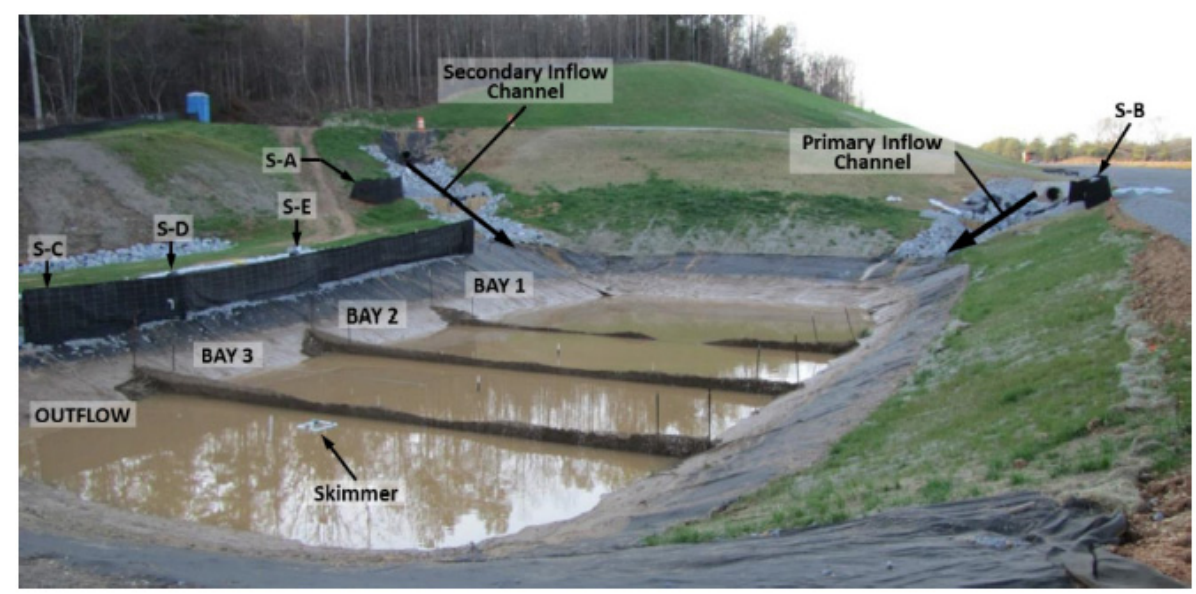

(b)

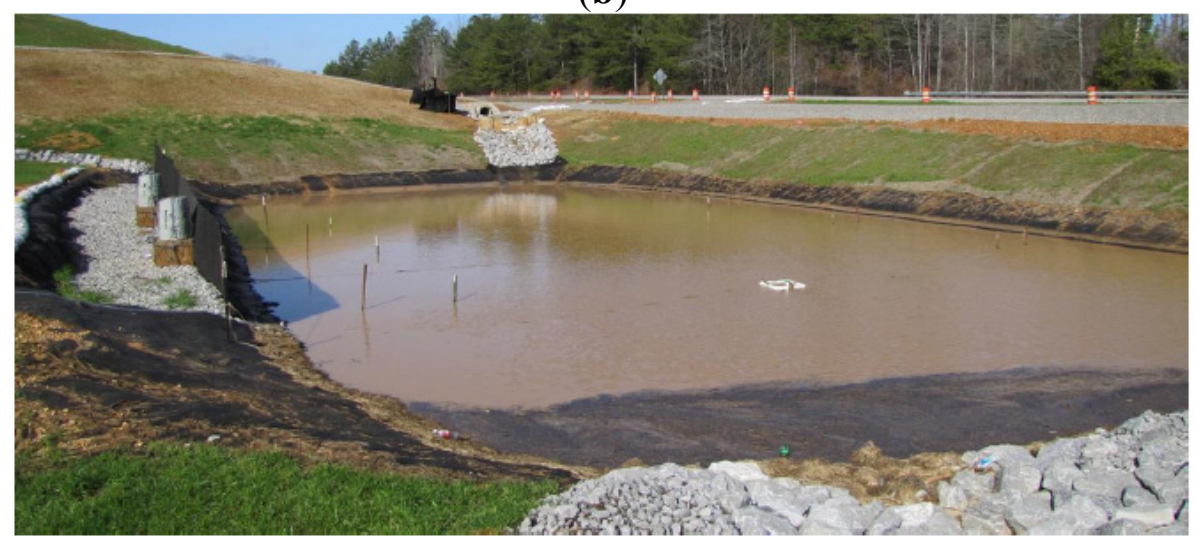

(c)

Figure 2. (a) Plan view (schematic diagram) and (b) a photo of actual project sediment basin layout and equipment locations, showing the condition when the water level was below the baffle height, and (c) the basin condition when water level breached above installed baffle height.

\subsection{Stormwater Runoff Sampling}

To understand the performance of the sediment basin, it was important to collect stormwater runoff samples at various locations to analyze for turbidity and TSS levels. Inflow sampler A was programmed to take $0.25 \mathrm{~L}$ stormwater runoff samples for every $1.42 \mathrm{~m}^{3}$ of inflow passing over the weir in the secondary inflow channel. Inflow Sampler B was programmed to take a $0.25 \mathrm{~L}$ sample for every $4.25 \mathrm{~m}^{3}$ of inflow passing over the weir in the primary inflow channel, since inflow volumes were much larger in comparison to the secondary inflow channel.

Due to variations of depth, intensity, and duration of rainfall events and variations in the contributing drainage area of the construction site, runoff rates, volumes, and durations varied greatly from one rainfall event to another. Due to these variances, it was difficult to program the samplers to collect adequate inflow samples for different rainfall events to characterize inflows into the basin. ISCO 6712 samplers in the primary and secondary inflow channels were set to collect samples at fixed inflow volumes passing over the weirs rather than at fixed time intervals. This protocol was decided because inflow rates were unsteady and dependent on individual rainfall characteristics. The determination to collect stormwater samples for every 1.42 and $4.25 \mathrm{~m}^{3}$ of inflow passing over the weirs was determined 
based on historical rainfall events that occurred in the study area and runoff estimations; a function of the contributing area and rainfall event.

For each inflow sampler, four $0.25 \mathrm{~L}$ samples were collected in a single $1 \mathrm{~L}$ bottle, creating a composite stormwater runoff sample to provide a measure of incoming water quality over the course of a rainfall event. In total, each of the inflow samplers had the capability of collecting up to $96,0.25 \mathrm{~L}$ samples in a single program spanning a single rainfall event with a combined maximum inflow volume of $543.7 \mathrm{~m}^{3}$. The ideal method to program a sampler to capture adequate and representative samples is to adjust the sampler program based on runoff modeling and rainfall forecasts so that an adequate number of inflow samples are always collected for various rainfall events with small and large rainfall depths. However, this is difficult to implement due to the lack of rainfall forecast information and forecast accuracy for a particular area. Typically, weather forecasts provide the probability of having a rainfall event without projecting rainfall depth and duration. In this study, the programs for the ISCO 6712 samplers were fixed for all 16 events monitored. This type of programming resulted in collecting minimal inflow samples for events with relatively small rainfall depths as discussed later. For example during one case within the study period, the samplers used 23 bottles to collect samples for a morning rainfall event and only had one collection bottle left for the subsequent afternoon rainfall event. No detailed information is available in the literature providing guidance on programming the sampler to collect a representative number of stormwater samples over the entire inflow hydrographs of natural rainfall events.

Sampler C was activated once $5.7 \times 10^{-5} \mathrm{~m}^{3} / \mathrm{s}$ of outflow was detected by an ISCO 750 (Teledyne Technologies, Inc., Thousand Oaks, CA, USA) area velocity flow module (Figure 2a) inserted into the outlet pipe of the skimmer. Sampler $\mathrm{C}$ acquired water quality samples from inside the filter grate of the skimmer. Sampler C collected a sample immediately after it was activated by the flow module and continued collecting samples at one-hour intervals until the program was complete, spanning a 24-h period of time and collecting a total of 24, $1 \mathrm{~L}$ stormwater samples.

Two other sampler units, Samplers D and E, were positioned within the sediment basin (Figures 1 and 2) to collect water quality samples from a water depth of $0.45 \mathrm{~m}$ from the bottom of the basin. The suction heads for the samplers were positioned directly in the middle of Bay 2 (between the first and second baffles, with respect to flow) and in the middle of Bay 3 (between the second and third baffles, with respect to flow). Samplers D and E were connected directly to Sampler C via a custom "Y-cable". This enabled the program for Samplers D and E to collect a sample in sequential order after Sampler C had completed each sampling cycle.

\subsection{Turbidity and TSS Measurements of Stormwater Runoff Samples}

All stormwater samples gathered by the sampling units were transported back to the laboratory for analysis of turbidity and TSS. This allowed for water quality measurements of stormwater runoff at the inflow (just before the weir), within the various bays of the basin, and outflow to be determined. The water quality within the basin was evaluated to allow for determining the settling effect along the flow path from inflow to outflow (as a result of gravity) and any settling enhancement caused by the addition of PAM in the inflow channel and the baffles used within the basin. 
Turbidity was measured using a portable HACH $2100 \mathrm{Q}$ portable turbidimeter (HACH Company, Loveland, CO, USA). The maximum turbidity reading on this instrument is 1000 NTU. In cases where samples exceeded the maximum turbidity, the test sample was diluted using a 1:2 ratio of low-turbidity deionized water according to instructions given in the "Sample Dilution" section of HACH Method 8366 [30]. TSS was determined using vacuum filtration according to the "Determining Total Suspended Solids" section of HACH Method 8366 [30].

\subsection{Soil Samples for Determining Particle-Size Distribution}

The particle-size distribution of sediment entrained in sediment-laden stormwater is one of the most critical pieces of information required when assessing sediment basin performance. It is costly and time consuming to determine the particle-size distributions for all inflow and in-basin samples collected during the study for large volumes of stormwater emanating from the contributing drainage area into the sediment basin. Therefore, only the particle-size distributions of raw soils in the construction site and sediment captured in the basin at the conclusion of the study were determined using the standard test method [31]. An assumption was made that the particle-size distributions of sediments captured by the basin should be similar to the particle-size distribution of raw soils collected on-site within the contributing drainage area.

To obtain the particle-size distributions of sediments deposited in the basin, sediment samples were taken at the conclusion of the basin monitoring period in the middle of each bay (Figure 2), with respect to the length of the basin. Three samples were collected in each bay (Bay 1, 2, 3, and 4) with respect to the width of the basin (roughly $2.5 \mathrm{~m}$ apart between samples). A total of 12 sediment samples were collected and dried in an oven before the standard test was performed for each sample.

\subsection{Sediment Basin Survey}

An initial, pre-evaluation survey of the sediment basin was performed by ALDOT surveyors immediately after basin construction and prior to the deployment of ISCO sampling units to establish a baseline sediment basin volume. A post-evaluation survey was conducted by the researchers at the end of the monitoring period to determine the volume of sediment captured. Both surveys were performed using Total Stations that provided three-dimensional coordinates of measured points within the basin. To determine the volume difference in the basin due to deposited sediments, a MicroStation (Bentley Systems, Inc., Exton, PA, USA) was used to develop a three-dimensional digital elevation model of the basin. Accuracy of the models was inspected to identify irregular topography of deposited sediment accumulation that did not correlate with visual observations. A retained sediment volume report was then generated by MicroStation, noting the net change in volume that was determined by subtracting the end-volume of the post-evaluation survey from the original volume of the pre-evaluation survey.

\section{Sediment Basin at Franklin County, AL, USA}

\subsection{Study Site}

The $12.5 \mathrm{~km}$ highway construction project consisted of constructing additional lanes on SR-24 from the east of Red Bay to Dempsey in Franklin County, AL. Figure 2 provides a plan view along with an 
isometric view of the actual sediment basin monitored as part of this study along with the placement of monitoring equipment. This was the first ALDOT implementation of the 2009 sediment basin design configuration (Figure 1). An equipment installation plan (Figure 2a) was developed prior to construction of the sediment basin. The outflow through the floating skimmer (Figure 2b,c) did not directly discharge into an adjacent stream, but was discharged into an infiltration basin for additional detention time and further water quality protection of the adjacent stream.

The volume of the sediment basin was originally designed to accommodate $512.3 \mathrm{~m}^{3}$ of stormwater runoff. The bottom length and width of the basin were designed as $23.2 \mathrm{~m}$ by $7.0 \mathrm{~m}$, respectively; resulting in a length to width ratio that was $3.3: 1$, exceeding the minimum $2: 1$ ratio suggested by the Alabama Handbook [7]. A minor field adjustment during construction added an extra $0.46 \mathrm{~m}$ of depth ( $74.2 \mathrm{~m}^{3}$ of additional volume of storage) to the basin. This added volume is for sediment storage and dead storage. Thus, the as-built storage volume became $574.5 \mathrm{~m}^{3}$.

The 2006 design standard requires a minimum basin storage of $126.0 \mathrm{~m}^{3} /$ ha of contributing area draining into the basin [5]. The total contributing watershed area of the basin monitored was $37,272 \mathrm{~m}^{2}$; therefore, the sediment basin was originally designed and sized using the 2006 design standard. This design limits a sediment basin to have sufficient volume to capture $12.7 \mathrm{~mm}$ of effective rainfall per hectare of disturbed area [32].

A $63.5 \mathrm{~mm}$ skimmer shown in Figures 1 and 2, which can have a maximum $63.5 \mathrm{~mm}$ orifice size, was used as the primary dewatering or outflow control device for the basin. The skimmer was level at $0.46 \mathrm{~m}$ above the basin floor. The flow rate from the skimmer was field measured to be $0.0014 \mathrm{~m}^{3} / \mathrm{s}$. The dewatering time of the basin varies with the water level inside the basin. When the basin is full at $1.98 \mathrm{~m}$ in depth, the dewatering time is 4.05 days $(97.3-\mathrm{h})$ and discharges a total of $500 \mathrm{~m}^{3}$ stormwater runoff from the basin into the infiltration basin, excluding dead storage [33].

Based on construction-site soil samples, Applied Polymer Systems (APS) Inc. (Atlanta, GA, USA) recommended using a type $706 \mathrm{~B}$ PAM floc block with a reaction or contact time between 40 and $45 \mathrm{~s}$. The recommended dosage rate was 0.0032 to $0.0038 \mathrm{~m}^{3} / \mathrm{s}$ of flow per each PAM block placed in a series or in a row.

\subsection{Data Collection Phases}

The total contributing drainage area draining to the basin was constantly evolving during the first four months of the project. Due to the construction progress on a large grading operation (cut) taking place in the upstream area of the basin (Figure 2b), the data collection effort was divided into two phases. Two inflow channels were constructed and used to convey stormwater runoff into the basin. During the first phase (Phase I-15 to 29 November 2011) of monitoring, a single inflow channel (identified as the secondary inflow channel in Figure $2 b$ ) was constructed to carry stormwater runoff into the sediment basin. During the second phase (Phase II-30 December 2011 to 16 February 2012), two inflow channels existed as a result of a newly added inflow channel acting as the primary inflow channel for the basin. The ISCO 6712 Sampler B was used to monitor the inflow of stormwater into the basin from the primary inflow channel that was constructed parallel to the constructed road bed, and Sampler A monitored inflow from the secondary inflow channel that conveyed runoff emanated from the hillside as shown in Figure 2. 


\section{Performance Data of the Sediment Basin}

\subsection{Phase I Results}

The total rainfall depths and the maximum five-minute rainfall intensities for the two events (16 November 2011 and 5 December 2011) during Phase I are shown in Table 1. In addition, five rainfall events resulted in very few inflow samples being collected during Phase I and were not included in the statistical summary provided in Table 1. However the ISCO samplers did collect stormwater samples in Bays 2 and 3 along with the outflow, which allowed us to understand the sediment settling characteristics in the basin as documented by Logan [33]. Even though the total rainfall depths for both events (16 November 2011 and 5 December 2011) were almost the same; peak discharge of stormwater runoff on 16 November $2011\left(0.095 \mathrm{~m}^{3} / \mathrm{s}\right.$, Figure 3) was much higher than that on 5 December 2011 $\left(0.035 \mathrm{~m}^{3} / \mathrm{s}\right.$, Figure 3$)$. This was primarily due to the difference in rainfall intensity even though other factors (e.g., grading activity) may also have had an effect. In Phase I of construction, vegetation or ground cover changed over time. The total inflow runoff volume into the basin was $196.5 \mathrm{~m}^{3}$ for the rain event on 16 November 2011 when the vegetation cover was approximately $10 \%$. The inflow volume was $176.1 \mathrm{~m}^{3}$ for the rain event on 5 December 2011 after more vegetative growth and ground cover (i.e., approximately 25\%) had been established. Based on the depth-storage curve, the maximum water depths in the basin were about $1.02 \mathrm{~m}$ and $0.94 \mathrm{~m}$, including $0.46 \mathrm{~m}$ of dead storage $\left(74.2 \mathrm{~m}^{3}\right)$, on 16 November 2011 and 5 December 2011, respectively. Observed inflow turbidity and TSS for the 16 November 2011 rain event had average values of $5855 \mathrm{NTU}$ and $5430 \mathrm{mg} / \mathrm{L}$, respectively. Average observed turbidity and TSS were 1989 NTU and $1305 \mathrm{mg} / \mathrm{L}$ for the 5 December 2011 rain event due to smaller rainfall intensity and more vegetative cover despite experiencing almost the same total rainfall depth.

Table 1. Statistical summary of turbidity and total suspended solids (TSS) of inflow stormwater samples.

\begin{tabular}{|c|c|c|c|c|c|c|c|c|c|c|}
\hline \multirow{2}{*}{ Date $^{1}$} & \multirow{2}{*}{$\begin{array}{c}\text { Rainfall } \\
{[\mathrm{mm}(\mathrm{mm} / \mathrm{h})]^{2}}\end{array}$} & \multirow{2}{*}{$\begin{array}{l}\text { No of } \\
\text { Data }\end{array}$} & \multicolumn{4}{|c|}{ Turbidity (NTU) } & \multicolumn{4}{|c|}{ TSS (mg/L) } \\
\hline & & & Max & Min & Avg. & STD & Max & Min & Avg. & STD \\
\hline 16 November $2011^{3}$ & $34.3(56.3)$ & 23 & 10,656 & 1030 & 5855 & 2582 & 10,545 & 790 & 5430 & 2689 \\
\hline 5 December $2011^{3}$ & $27.7(27.4)$ & 21 & 2724 & 878 & 1989 & 446 & 1950 & 465 & 1305 & 380 \\
\hline 17 January $2012^{4}$ & $31.0(83.3)$ & 28 & 28,352 & 3488 & 9902 & 6234 & 26,325 & 2720 & 7433 & 5632 \\
\hline 26 January $2012^{4}$ & $18.5(12.2)$ & 24 & 785 & 191 & 506 & 149 & 435 & 95 & 275 & 75 \\
\hline 1 February $2012^{4,5}$ & $11.7(24.4)$ & 24 & 3688 & 508 & 1905 & 1067 & 2645 & 250 & 1105 & 745 \\
\hline 4 February $2012^{4}$ & $22.4(15.2)$ & 27 & 3892 & 616 & 1944 & 914 & 2315 & 255 & 1068 & 561 \\
\hline
\end{tabular}

Notes: ${ }^{1}$ Eight rainfall events with a few inflow samples and two events on 7 and 8 January 2012 in which the samplers were not able to collect inflow samples are not listed in the table above. These rainfall events occurred on 27 November (two events), 28 November, 22 and 26 December in 2011 for Phase I; and on 7, 8, 11, 22 January, and 1 February (evening event) in 2012 for Phase $\mathrm{II}^{2}{ }^{2}$ total rainfall in $\mathrm{mm}$, and the number inside brackets is the maximum 5 -min rainfall intensity in $\mathrm{mm} / \mathrm{h} ;{ }^{3}$ rainfall event during the Phase I data collection; ${ }^{4}$ rainfall event during the Phase II data collection; ${ }^{5}$ rainfall event in the morning of 1 February 2012 (Phase II data collection, there is another event in the afternoon on the same day).

Figure 3 shows that the first measured turbidity (1646 NTU), when outflow began discharging through the skimmer at 9:07 am on 16 November 2011, was much lower than the maximum inflow 
turbidity of 10,656 NTU (Table 1). This is primarily due to the basin containing inflow runoff collected in the dead storage for approximately $27 \mathrm{~min}$ (inflow starting on 8:40 am, Figure 3) prior to the initiation of discharge. Measured turbidity at Bay 2, Bay 3, and outflow, decreased with time to about 240 NTU after $24 \mathrm{~h}$ of data collection (Figure 3). The turbidity of 240 NTU was a $98 \%$ reduction from the maximum inflow turbidity and a $70 \%$ reduction from the first measured turbidity at the outflow. For the 5 December 2011 rain event, the first measured turbidity at the skimmer was only 60 NTU when the outflow started at 3:37 P.M., 15 min after the inflow started at 3:22 P.M. This was because the basin contained less turbid water (after most sediments settled out of suspension) from a previous rainfall event (27-28 November 2011) that diluted the sediment-laden inflow [33]. Measured turbidity of the outflow through the skimmer increased to 1104-1112 NTU from 6:37 P.M. to 8:37 P.M. when sediment-laden stormwater continuously flowed into the basin, then started to decrease at 9:37 P.M. (964 NTU, Figure 3) after inflow stopped, eventually dropping to about $600 \mathrm{NTU}$ at the end of the $24 \mathrm{~h}$ data collection period. The turbidity measurement of 600 NTU was a $78 \%$ reduction from the maximum inflow turbidity ( $2724 \mathrm{NTU}$ ) and a $46 \%$ reduction from the maximum measured turbidity at the outflow (1112 NTU) for the 5 December 2011 rainfall event.

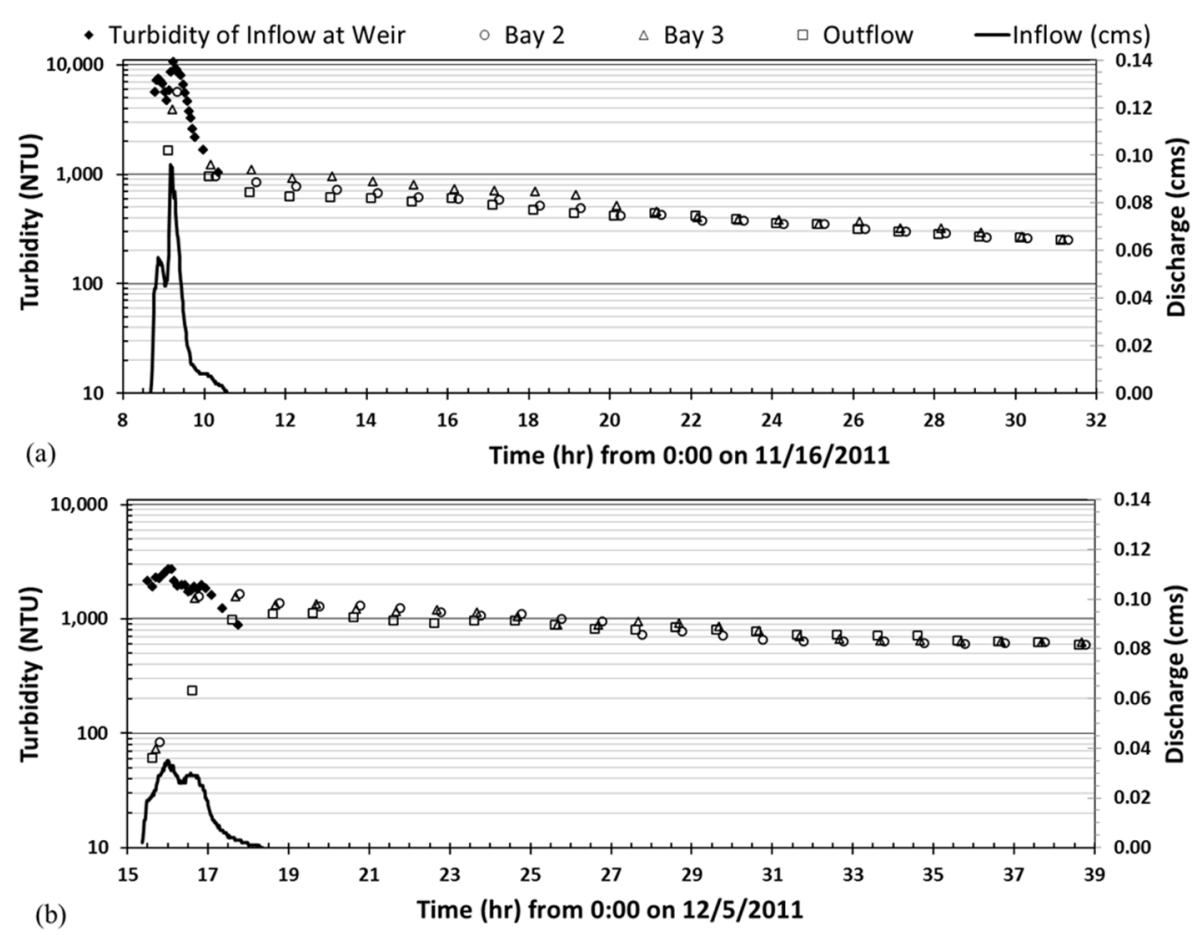

Figure 3. Time-series plots of inflow discharges $\left(\mathrm{cms}\right.$ or $\left.^{3} / \mathrm{s}\right)$ and measured turbidity (NTU) from stormwater samples collected at the inflow weir, Bay 2, Bay 3, and outflow of the basin: (a) for 16 November 2011 rain event and (b) for 15 December 2011 rain event during Phase I.

The difference in performance of the basin for these two rain events was primarily due to the construction contractor applying the correct soil specific PAM used on 16 November 2011 and incorrect PAM used on 5 December 2011. The cause of using incorrect PAM by the contractor is described in Section 5 "Lessons Learned". These variances in performance could also be attributed to different sediment particle sizes flowing into the basin: With more vegetation cover established on 5 December 
2011, lower percentage of coarser sediments and higher fraction of finer sediments could have washed into the basin (Figure 4a), resulting in a longer settling time of the smaller particles (requiring additional residence time).

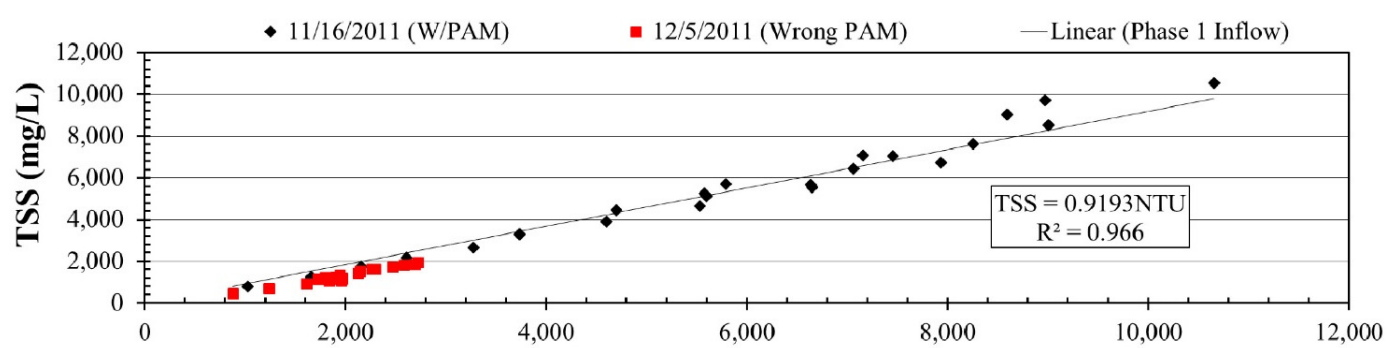

(a) Inflow

Turbidity (NTU)

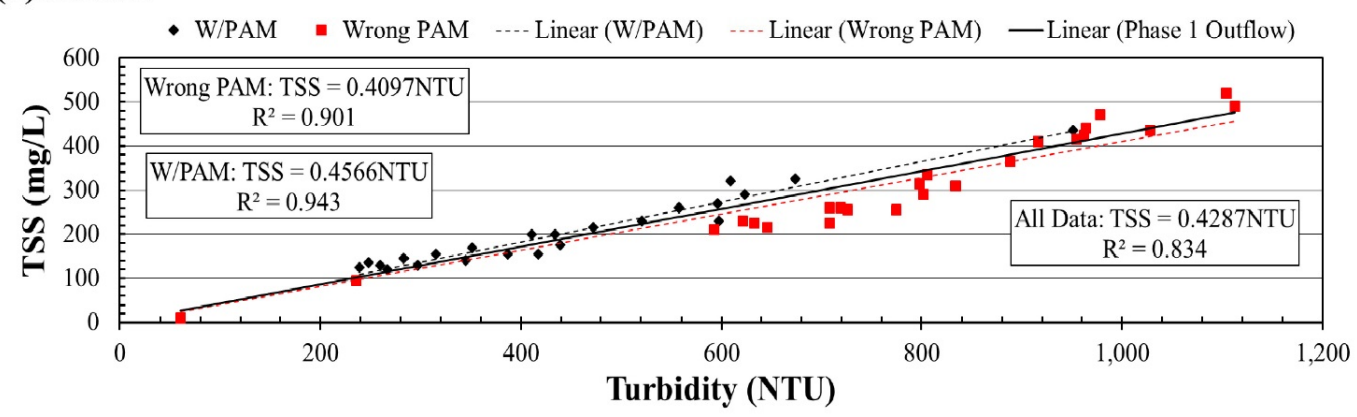

(b) Outflow

Figure 4. Total suspended solids (TSS) and turbidity correlations for the two data sets in Phase I: Different scales used in (a) and (b) for $x$ and $y$ axes.

Figure 3 also shows that measured turbidity using stormwater samples, collected at $0.46 \mathrm{~m}$ above the basin floor of Bay 2 and Bay 3, were somewhat higher than measured turbidity of outflow collected near the water surface (through the skimmer) in the first 12-h of data collection. After the 12-h data collection, measured turbidity values at Bay 2, Bay 3, and outflow are very similar (Figure 3) despite different depths used for the three stormwater sample collection locations. This suggests that the floating surface skimmer may not always improve discharge water quality when compared to a perforated riser structure - a similar finding from a study in North Carolina by McLaughlin et al. [17]. The larger and heavier particles settled first, after a certain retention time (e.g., 12-h for the basin), and only non-settleable, very fine sediments remained suspended in the basin. The skimmer did prevent the discharge of highly turbid water that contained heavy sediments in the first 12-h of the basin dewatering process.

TSS and turbidity correlations were determined separately for the inflow and outflow samples collected during Phase I (Figure 4) and Phase II [33] due to the fact that significantly different correlations exist between the heavier suspended sediments in the inflow and the finer fraction contained in the outflow. The slopes of the linear corrections between TSS and turbidity (NTU) were determined to be 0.9193 (Figure 4a) and 0.4287 (Figure 4b) for inflow and outflow data, respectively. The slopes of the linear relationships between TSS and turbidity for stormwater samples in Franklin County are similar to, but not the same as, the slopes determined from the data of five different sediment detention devices for a study in a North Carolina construction site without distinguishing inflow and outflow samples [13]. Compared to TSS analysis, turbidity is easier and quicker to measure, however the soil-specific relationship of TSS and turbidity has to be established for each monitoring site before one can predict 
TSS from turbidity [13]. The correlations of TSS and turbidity determined for outflow under W/PAM (16 November 2011) and wrong PAM (5 December 2011) conditions are similar (Figure 4b). This is most likely because large sediment particles (either natural or formed due to flocculation of PAM) had settled before reaching the outflow and finer particles near the water surface were about the same. The TSS data (red squares in Figure 4a) for the inflow on 5 December 2011 indicate that finer or lighter particles were washed into the basin from the site drainage areas as explained above.

\subsection{Phase II Results}

Ten rainfall events occurred during the second phase (Phase II) of the data collection effort, and fifteen 24-h data collection periods of stormwater samples were developed in the basin from 30 December 2011 to 5 February 2012. The data collection in each 24-h period was continuous as shown in Figure 5 . The event rainfall depths ranged from 6.6 to $31.0 \mathrm{~mm}$, and the maximum five-minute rainfall intensities for the events ranged from 6.1 to $88.4 \mathrm{~mm} / \mathrm{h}$. The rain event on 17 January 2012 had a $31.0 \mathrm{~mm}$ rainfall with a maximum five-minute rainfall intensity of $88.4 \mathrm{~mm} / \mathrm{h}$. The event on 17 January 2012 also had $15.2 \mathrm{~mm}$ of rainfall over a 15-min period (3:30 P.M. to 3:45 P.M.) that produced a large concentration of inflow. A full set of inflow samples was taken to allow for some representation of stormwater runoff entering the basin (Table 1). Measured turbidity for the concentrated inflow on 17 January 2012 ranged from 3488 to 28,352 NTU with an average value of 9902 NTU over the 1.5-h data sampling period, and corresponding TSS ranged from 2720 to $26,325 \mathrm{mg} / \mathrm{L}$ (Table 1 ). These data demonstrate that high intensity rainfall impulses can potentially erode a large amount of sediment from a construction site, generating inflows with very high turbidity and TSS, which creates an additional sediment load for the basin to treat.

The data collected during Phase II were divided into two conditions based on site flow characteristics: (1) "No PAM" (four events from 7 to 22 January 2012); and (2) "W/Limited PAM" (six events from 26 January to 5 February 2012). Due to the primary inflow channel and weir being improperly installed by the contractor, stormwater flowing into the basin through the primary inflow channel flowed around and under the weir. Under this condition, flow did not come in contact with the floc blocks that were placed on top of the riprap downstream of the weir; therefore, PAM was never introduced to the stormwater runoff during the first condition. After reinstallation of the weir on 24 January 2012, the weir was able to maintain proper function allowing water to flow over the spillway and into the basin. However, the amount of flow occurring over the weir (up to $0.06 \mathrm{~m}^{3} / \mathrm{s}$, Figure 5) resulted in a limited PAM treatment condition because the four PAM blocks placed in the inflow channel were only capable of dosing $0.0151 \mathrm{~m}^{3} / \mathrm{s}$ (240 gpm) of flow based upon manufacturer's recommendations.

Figure 5 shows example results of Phase II data collection, which includes: Time-series plots of five-minute rainfall intensity $(\mathrm{mm} / \mathrm{h})$ and measured turbidity from stormwater samples collected at Bays 2 and 3, and the outflow of the basin, for rain events from 26 to 30 January 2012 (top) and from 1 to 5 February 2012 (bottom). There were three 24-h data collection periods during and after the rainfall event on 26 January 2012, which gave us useful information on sediment settling over an extended period of time. Measured turbidity at the outflow slowly decreased from 905 to 243 NTU over three 24-h monitoring periods with a limited PAM treatment. The maximum turbidity during the event on 26 January 2012 was not very high because of low rainfall intensity, less than $12.2 \mathrm{~mm} / \mathrm{h}$ (Table 1). 

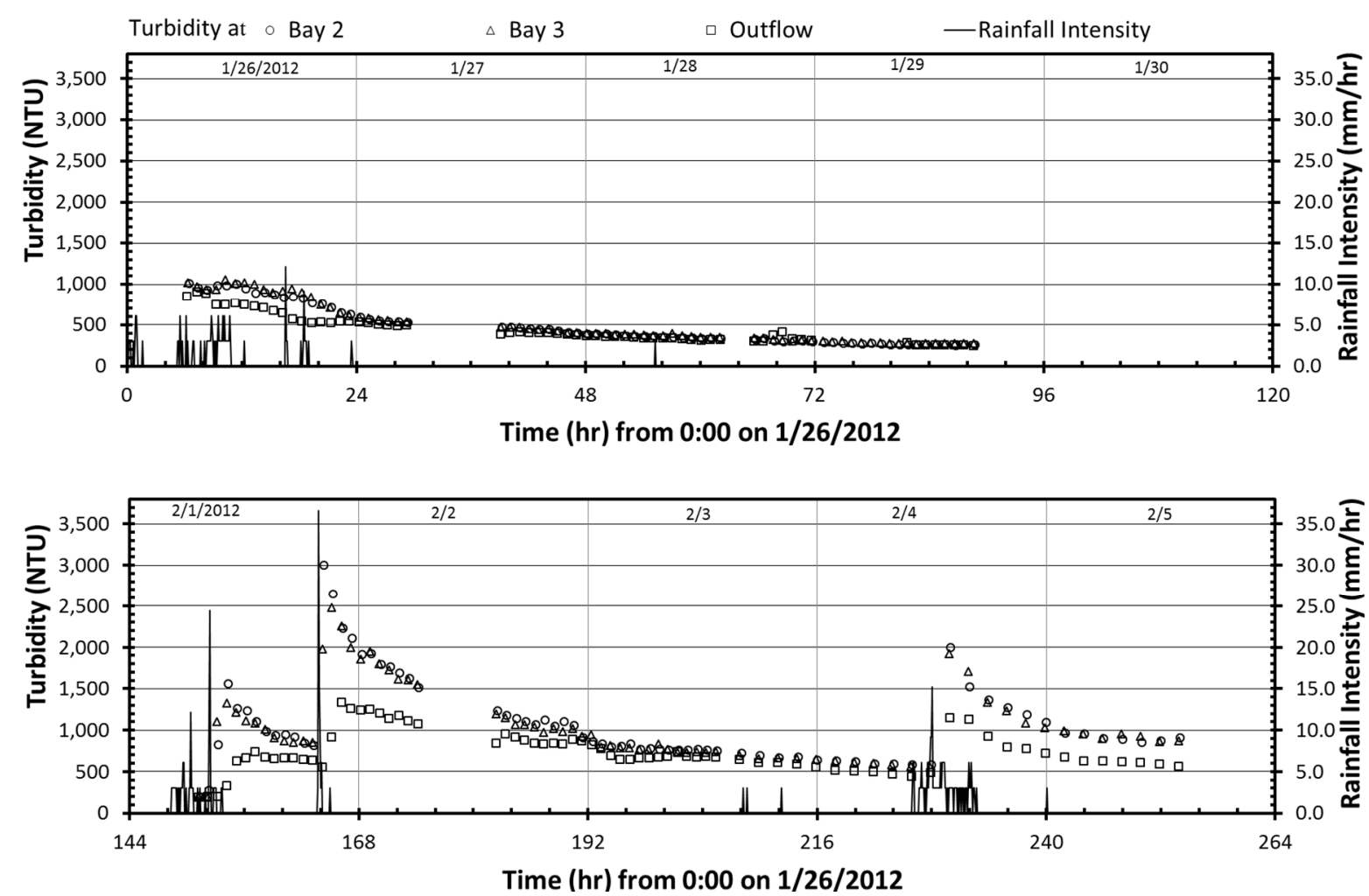

Figure 5. Time-series plots of five-minute rainfall intensity $(\mathrm{mm} / \mathrm{h})$ and measured turbidity from stormwater samples collected at the outflow, Bay 2, and Bay 3 of the basin for rain events from 26 January 2012 to 5 February 2012 (Phase II).

There were two rain events on 1 February 2012, from 4:25 A.M. to 9:40 A.M. and from 7:40 P.M. to 8:05 P.M. The morning event on 1 February 2012 had $11.7 \mathrm{~mm}$ rainfall with a maximum five-minute intensity of $24.4 \mathrm{~mm} / \mathrm{h}$ and resulted a maximum turbidity of $3688 \mathrm{NTU}$ at the inflow weir (Table 1). The evening event on 1 February 2012 had only $6.4 \mathrm{~mm}$ of total rainfall but had a maximum five-minute intensity of $36.6 \mathrm{~mm} / \mathrm{h}$. Measured turbidity at Bay 2 decreased from 1552 to 811 NTU (Figure 5) during, and a few hours following, the morning event. The turbidity jumped to 2996 NTU (Figure 5) due to the evening event on 1 February 2012. Measured turbidity at Bay 2 continued to decrease on 2 February and 3 February 2012 until the rainfall event started on 4 February 2012 that caused a turbidity increase to 1988 NTU. Figure 5 clearly shows the impacts of a subsequent rain event that followed a previous rain event on turbidity in Bay 2, Bay 3, and outflow. The sudden increases in turbidity and TSS [33] just after a subsequent rain event were a result of additional sediment-laden runoff with higher turbidity from the subsequent rain event and possible resuspension of deposited sediment within the basin when additional inflow was introduced.

When the basin was partially filled with runoff and baffle height restricted short circuiting (Figure 2b), Figure 5 clearly shows measured turbidity of collected stormwater samples at $0.46 \mathrm{~m}$ above the basin bottom at Bay 2 and Bay 3 could be significantly larger than turbidity of the outflow measured near the water surface. For example, measured turbidity at the outflow followed by the evening event on 1 February 2012 reached a maximum value of 1330 NTU in comparison to the maximum values of 2996 NTU and 2472 NTU near the bottom of Bay 2 and Bay 3, respectively (Figure 5), which illustrates the benefit of using a floating surface skimmer as the primary dewatering device. 
The data analysis [33] shows that turbidity and TSS in the basin exponentially decreased with time when there was no inflow entering the basin:

$$
\begin{gathered}
N T U(t)=N T U\left(t_{0}\right) \cdot \exp \left(-k_{1} \cdot t\right) \\
\operatorname{TSS}(t)=T S S\left(t_{0}\right) \cdot \exp \left(-k_{2} \cdot t\right)
\end{gathered}
$$

where $t$ is the time in hours after the reference time $t_{0}, k_{1}$ and $k_{2}$ are decay regression constants $\left(\mathrm{h}^{-1}\right)$ for turbidity and TSS, respectively. The data analysis indicated that the decay constants of the exponential settling rates ranged from -0.008 to $-0.073 \mathrm{~h}^{-1}$ [33], which were equivalent to a $17 \%$ to $83 \%$ reduction in turbidity or TSS per day. During the rainfall period, turbidity and TSS in the basin varied with time depending on several factors: (1) turbidity of inflow; (2) resuspension of previous deposited sediment; and (3) whether the basin was empty or partially filled with stormwater from a previous rainfall event (Figure 2), as illustrated in Figure 5.

\subsection{Overall Basin Performance}

Due to data collection complications in the basin, only two events (16 November 2011 and 5 December 2012) were used to quantify the sediment removal efficiency of the basin during Phase I. The event mean concentrations (EMCs) [34] for TSS (mg/L) and turbidity (NTU) were calculated for inflow and outflow of the basin and reported in Table 2 including the total sediment load $(\mathrm{kg})$. Calculated sediment leaving the basin through outflow was only $25.3 \mathrm{~kg}$, therefore, the efficiency of the basin to remove TSS was $97.9 \%$ for the rainfall event on 16 November 2011. TSS load of the outflow on 5 December 2011 was $36.6 \mathrm{~kg}$, which was higher than the outflow sediment load on 16 November 2011, and may be due to suspension of fine sediments deposited in the basin from previous rainfall events. Plus the incorrect PAM being used by the contractor, the efficiency of the basin to remove TSS was $83.7 \%$ for the rainfall event on 5 December 2011.

Table 2. Event mean concentration (EMC) for turbidity, TSS, and removal efficiency for

\begin{tabular}{|c|c|c|c|c|c|c|c|c|c|}
\hline \multirow[b]{2}{*}{ Rainfall Event } & \multicolumn{3}{|c|}{ Inflow (Weir) } & \multicolumn{3}{|c|}{ Outflow (Skimmer) } & \multicolumn{3}{|c|}{ Removal Efficiency } \\
\hline & $\begin{array}{c}\text { EMC TSS } \\
(\mathrm{mg} / \mathrm{L})\end{array}$ & $\begin{array}{c}\text { EMC Turbidity } \\
\text { (NTU) }\end{array}$ & $\begin{array}{c}\text { TSS Load } \\
(\mathrm{kg})\end{array}$ & $\begin{array}{c}\text { EMC TSS } \\
(\mathrm{mg} / \mathrm{L})\end{array}$ & $\begin{array}{c}\text { EMC Turbidity } \\
\text { (NTU) }\end{array}$ & $\begin{array}{c}\text { TSS Load } \\
(\mathrm{kg})\end{array}$ & by TSS & by NTU & by Load \\
\hline 16 November 2011 & 6519.6 & 6830 & 1197.7 & 221.5 & 478 & 25.3 & $96.6 \%$ & $93.0 \%$ & $97.9 \%$ \\
\hline 5 December 2011 & 1331.2 & 2024 & 224.0 & 319.6 & 793 & 36.6 & $76.0 \%$ & $60.8 \%$ & $83.7 \%$ \\
\hline
\end{tabular}
two rain events.

To quantify total sediments captured by the basin during the study period (all 16 rainfall events), the post-evaluation survey on 26 April 2012 was compared to the pre-evaluation survey of the basin [33]. Total retained sediment volume for the basin was $48.1 \mathrm{~m}^{3}$ that resulted from sediment-laden runoff generated from rainfall events from 13 September 2011 (when the basin construction was complete) to 26 April 2012. The retained sediment volume occupied $65 \%$ of the basin's dead storage $\left(74.2 \mathrm{~m}^{3}\right)$ and was only $8.4 \%$ of the total sediment basin volume $\left(574.5 \mathrm{~m}^{3}\right)$.

Figure 6 shows average particle-size distributions of raw soils and sediment deposited in each bay of the basin determined from three soil sample analyses. Each processed sample used $1000 \mathrm{~g}$ of soil sieved through No. 4 to 200 (particle sizes from 4.76 to $0.074 \mathrm{~mm}$ ) gradations. The settling velocities of 
suspended particles in a sediment basin depend on various factors such as particle size or diameter, shape, density, water temperature (viscosity), flow turbulent characteristics, wind wave, use of flocculants, type and amount of flocculants used, etc. From the particle-size distribution of raw soils, about $25 \%$ of sediments have particle diameters greater than $0.5 \mathrm{~mm}$ (coarse sand) with approximate settling velocity of 4.5-6.0 $\mathrm{m} / \mathrm{min}$ [35], which can settle out of suspension very quickly in the basin. About $47 \%$ of sediments are fine or medium-size sand with particle diameters ranging from 0.08 to $0.5 \mathrm{~mm}$ that have approximate settling velocity about $0.15-3.0 \mathrm{~m} / \mathrm{min}$ [35]. With $0.15 \mathrm{~m} / \mathrm{min}$ of settling velocity, the particle could take less than $15 \mathrm{~min}$ to settle from the surface to the bottom under full basin conditions (1.98 m depth). About $15 \%$ of sediments were silt, with particle diameters ranging from 0.002 to $0.05 \mathrm{~mm}$ that have approximate settling velocities ranging from 0.3 to $0.6 \mathrm{~m} / \mathrm{h}$ [35]; which would take less than $6.5 \mathrm{~h}$ to settle over $1.98 \mathrm{~m}$ of depth within the basin. The particle-size distribution (Figure 6) determined using sieve analysis did not report clay faction (diameter $<0.0001 \mathrm{~mm}$ ) in both the raw soil and deposited sediments. However, the settling behavior of sediments in the basin (Figures 3 and 5) indicates that the small percent of clay dominantly controlled and affected turbidity in the sediment basin after 7 -h of retention.

The particle-size distributions of deposited sediments indicate that in comparison to other bays and the raw soil, Bay 4 had finer sediments since the curve is above all other distribution curves (Figure 6). Bay 4 had $40 \%$ of particles less than $0.1 \mathrm{~mm}$ (fine sand). The particle-size distribution in Bay 3 is close to the distribution of raw soil. Bay 1 and Bay 2 contained a greater concentration of larger particles $(>0.2 \mathrm{~mm})$, and Bay 1 contained the lowest percentage of smaller particles with diameters less than $0.1 \mathrm{~mm}$.

In the post-evaluation survey [33] we collected the coir baffle materials: Three $0.36 \mathrm{~m}^{2}(0.6$ by $0.6 \mathrm{~m})$ samples were collected from each baffle. The clean coir baffle used in the basin was measured to be $975 \mathrm{~g} / \mathrm{m}^{2}$. Collected baffle samples between Bay 1 and 2, Bay 2 and 3, Bay 3 and 4 were weighted as 3263; 2005; and $1787 \mathrm{~g} / \mathrm{m}^{2}$; respectively [33]. Therefore, these baffles did capture sediments moving towards the outflow, and baffle densities indirectly indicate sediments from Bay 1 to Bay 4 decreased in particle size and density (became finer).

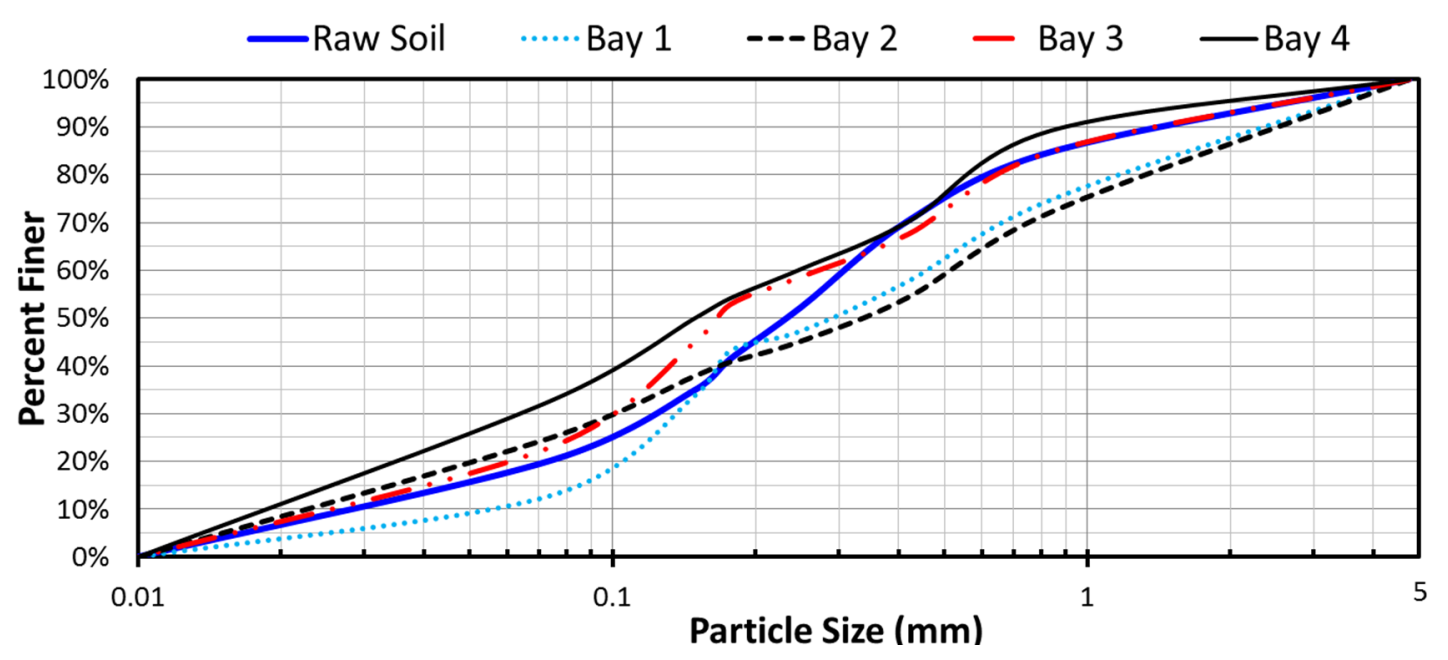

Figure 6. Particle-size distributions of raw soil at the construction site of the basin, deposited sediments in Bay 1, Bay 2, Bay 3, and Bay 4 of the basin at the end of data collection. 


\section{Lessons Learned}

When lessons learned are summarized and shared, it is beneficial to the professional community and for future studies monitoring sediment basin performance. The lessons learned are explained below as follows:

- The monitoring team needs to provide clear instructions to the construction contractor on where monitoring equipment will be located at the sediment basin. Figure 2 a shows a schematic diagram (using the original design drawing as background) of the sediment basin monitored in the study, providing the approximate locations of the monitoring equipment. Figure 2a was developed for the contractor to appropriately construct the basin (i.e., weir installation, baffle placement, site preparation for sampler's installation, etc.) for the researchers to install all monitoring equipment immediately after the construction of the sediment basin is complete. A similar diagram was not prepared for a different sediment basin in the same construction project, which was supposed to be monitored. Wet weather conditions prevented the contractor and researchers from properly installing the data collection equipment since site preparation instructions were not provided in advance to the contractor. This resulted in the site not being properly prepared when the basin was originally constructed and the researchers not being able to install monitoring equipment in a timely fashion. Therefore, this particular basin was not monitored and data was never collected resulting in a missed opportunity.

- The monitoring team and the basin design standards need to provide appropriate instructions to the contractor on the proper use, dosage, and placement of PAM floc blocks. For the 2009 sediment basin design used on the ALDOT construction project, the proper placement and number of PAM blocks are important to ensure that sediment-laden stormwater inflow is properly dosed to promote flocculation of suspended sediment and deposition within the basin. Figure 1 is a part of the project drawing for the construction project that shows the placement of four PAM floc blocks in the inflow channel downstream of the rock ditch check and weir structure. The drawing also includes a special project note (not shown in Figure 1) stating:

“4. Payment for polyacrylamide block will be paid under item 655-W. Four (4) blocks shall be placed at the inlet end of the basin. Block condition shall be monitored and blocks shall be replaced when they have degraded to the point they no longer appear to be effective."

The contractor followed the drawing and the special project note verbatim and installed four PAM floc blocks after the inflow weir without considering the actual amount of flow expected from the contributing drainage area.

- The monitoring team needs to provide the contractor with specific instructions on using the correct type of PAM that is decided based upon laboratory testing of the local site soil properties. Appropriate PAM floc blocks were purchased by the contractor from APS after the soil samples from the construction site were tested by the manufacturer. After the 16 November 2011 rain event, the contractor cleared a large amount of small \#4 aggregate from the rock ditch check that had washed into the weir and accidently removed the correct PAM. The contractor then placed four new PAM floc blocks in the channel downstream of the weir, but during a visit to the basin 
following the rain event on 5 December 2011, the researcher discovered that those PAM blocks were not the soil prescribed type of PAM (possibly left over from a previous project). Therefore, during the Phase I data collection effort, two conditions were observed: (1) correct PAM placement and (2) incorrect (i.e., wrong type) PAM placement in the inflow channel. These two conditions are referred to as " $\boldsymbol{w} / \boldsymbol{P} \boldsymbol{A M}$ ' and "w/wrong $\boldsymbol{P} \boldsymbol{A M}$ ', respectively, when data collection results are discussed.

- If a weir is used for data collection, clear instructions need to be provided to the contractor on the proper installation. The runoff should not be allowed to flow around and under the weir, which will result in inaccurate flow rate measurements. As a result of improper construction and installation of the weir at the primary inflow channel by the contractor (when the monitoring team was not on-site), no or a few inflow samples were collected for three rainfall events (on 7, 8, and 11 January 2012 in Table 1) during Phase II data collection. After the weir was appropriately reinstalled on 24 January 2012, only four sets of complete inflow data were collected for Phase II, which are listed in Table 1.

- The baffle height requirement should be clearly stated (e.g., in notes) and not just shown in the design drawing for the construction and installation of a sediment basin. The purpose of the baffles are to help slow inflow velocities and distribute the flow across the entire width of the basin, thereby creating favorable conditions for sedimentation [7] to occur under non-turbulent flow conditions as shown in Figure $2 b$. The problem observed during data collection, as shown in Figure 2c, was that when runoff from a rain event completely filled the basin, the water level within the basin overtopped the baffles, creating a fully mixed condition within the basin, disabling the primary function of the baffles. The runoff from the rainfall event on 26 January 2012 (Figure 5 top) was fully contained in the basin and the water level was lower than the baffle height, therefore, outflow turbidity was low. However, the rainfall events on 1 February 2012 and 4 February 2012 (Figure 5 bottom) created overflow through the spillway and the water level was higher than the baffle height, therefore, outflow turbidity was much higher. In the case of the basin monitored, the height of the baffles was $1.22 \mathrm{~m}$ when the contractor used available coir baffle materials, whereas the full depth of the sediment basin was $1.98 \mathrm{~m}$. For the baffles to function properly, as designed, it is imperative that the height of the baffles be greater than the maximum potential water level within the sediment basin, just prior to discharge over the emergency spillway.

\section{Challenges of Data Collection and Basin Operations}

There were also various challenges associated with the data collection efforts and basin operations for an ongoing construction project, which are summarized below:

- There were six rainfall events that occurred during Phase I of the construction effort, and complete data collections were developed for two of these six rainfall events (16 November 2011 and 5 December 2011, Figure 3). Freezing temperatures and redirecting the runoff as construction progressed, prevented complete data collection for the other four events.

- Due to the large concentrated inflow created on 17 January 2012, damage occurred to the primary inflow channel and weir, rendering the weir useless for future data collection until properly repaired. 
- To ensure adequate performance, it is important that the basin is sized appropriately to capture and detain stormwater runoff for the maximum potential drainage area contributing runoff into the basin during the life of the project.

- Resuspension of deposited sediments from previous rainfall events resulted in higher turbidity in the basin and reduced the efficiency of the basin. The period with no rain after 26 January 2012 allowed sediments to continuously settle (Figure 5) but three rain events from 1 to 4 February 2012 resulted in complex and dynamic variations of turbidity and TSS in the basin under a limited PAM condition.

- The turbidity of sediment-laden inflow from a construction site actually depends less on the total amount of rainfall from an event (e.g., 2-year, 24-h design storm) but more on rainfall intensity. For example, the rainfall event on 17 January 2012 had a total rainfall depth of $31.0 \mathrm{~mm}$ with a maximum five-minute rainfall intensity of $88.4 \mathrm{~mm} / \mathrm{h}$ that generated inflow with maximum measured turbidity and TSS of 28,352 NTU and 26,325 mg/L, respectively. The total rainfall depth for the event was much less than $124.5 \mathrm{~mm}$ rainfall for a 2-year, 24-h storm in Franklin County, $\mathrm{AL}$, but the maximum five-minute rainfall intensities for the 2-year and 10-year, 24-h design storms are only $11.2 \mathrm{~mm} / \mathrm{h}$ and $16.3 \mathrm{~mm} / \mathrm{h}$, respectively, using Type II NRCS rainfall distribution [36]. A basin designed using a 2-year, 24-h storm would have adequate storage volume to hold runoff generated from the event, but whether the basin can sufficiently handle high turbidity generated from other high intensity rainfall impulses is unknown and needs to be further studied.

- It is difficult and challenging to dose sediment-laden stormwater inflow with the exact amount of flocculating agent across all rainfall events since rainfall is a stochastic variable. This can be considered as a challenge for specification writing by agencies and basin operations by contractors. This will be discussed in detail in the next section.

\section{Discussion and Recommendations}

The current USEPA's National Pollutant Discharge Elimination System (NPDES) Construction General Permit provides sediment basin design requirements in Section 2.1.3.2-a-i to "Provide storage for either (1) the calculated volume of runoff from a 2-year, 24-h storm; or (2) 3600 cubic feet per acre drained" [37]. The 2009 Alabama Handbook [7] requires a minimum volume of a sediment basin to be 3600 cubic feet per acre (i.e., $251.9 \mathrm{~m}^{3} / \mathrm{ha}$ ) of the contributing drainage area. Observed inflow volumes to the study basin for four events occurred on 16 November 2011, 5 December 2011, 1 February 2012, and 4 February 2012 were $195.8 ; 176.1 ; 620.8$; and $805.8 \mathrm{~m}^{3}$ [33], respectively. Using $251.9 \mathrm{~m}^{3} / \mathrm{ha}$ design standard the basin associated with 3.73 ha watershed would provide $938.9 \mathrm{~m}^{3}$ of storage, which would be sufficient to hold the observed volumes produced by rain events during both Phase I and Phase II data collections. The $251.9 \mathrm{~m}^{3} /$ ha design standard is still insufficient for the basin to detain the runoff volume of a 2-year, 24-h storm event $\left(2749.5 \mathrm{~m}^{3}\right.$ determined from a rainfall-runoff modeling); therefore, the basin is significantly undersized with respect to handling 2-year, 24-h event runoff volumes.

USEPA [4] estimated the storage volume of a sediment basin using a weighted runoff coefficient based on hydrologic soil group distributions and the 2-year, 24-h storm depth for a selected location in each state. USEPA [4] calculated an advanced-treatment-system storage requirement for Alabama to be $825.5 \mathrm{~m}^{3} /$ ha using the 2-year, 24-h rainfall depth in Montgomery, which is 3.3 times larger than the 
current minimum storage requirement in Alabama. An under-designed sediment basin (from a volumetric standpoint) more frequently allowed highly turbid sediment-laden runoff to directly flow over the emergency spillway to a downstream receiving water body. During data collection, five rainfall events occurred on 11, 17, 22 January 2012, 1 and 4 February 2012 resulted in overflow through the spillway of the basin into the infiltration basin. The rainfall events on 17 January 2012 and 1 February 2012 filled the basin up from a zero-outflow point to generate overflow, while the other three events resulted in overflow when the basin was partially full of sediment-laden stormwater runoff from a previous rainfall event (water level was above the $0.46 \mathrm{~m}$ dead storage).

In addition, the proper placement of PAM floc blocks is crucial to ensure that sediment-laden stormwater inflow is properly dosed to promote flocculation of suspended sediment and deposition within the basin. Based on the APS's dosage recommendation, four PAM floc blocks placed in the inflow channel downstream of the weir by the contractor would handle a maximum flow of 0.0126 to $0.0151 \mathrm{~m}^{3} / \mathrm{s}$. Figure 7 presents the observed inflow hydrographs for several rainfall events from the Phase I and Phase II data collection, including average inflow rates of 2-year, 24-h and 10-year, 24-h design storms for the basin studied in Franklin County, AL. The 2009 Alabama Handbook [7] suggests designing sediment basins using a 2-year, 24-h rainfall and spillway using a 10-year, 24-h rainfall. Observed inflow rates resulted from these five events exceeded the effective flow rate limit $\left(0.0151 \mathrm{~m}^{3} / \mathrm{s}\right)$ of the four PAM floc blocks that were in place in both inflow channels (Figure 4) during both phases of data collection. Runoff hydrographs of design storms were modeled using NRCS 24-h rainfall distribution (Type II for Franklin County, AL, USA), hydrologic soil group C for newly graded area (Curve Number CN = 91), and a NRCS dimensionless unit hydrograph. The 2-year and 10-year, 24-h rainfall depths are $99.1 \mathrm{~mm}$ and $142.2 \mathrm{~mm}$ in Franklin County, AL, USA; and produce $2749 \mathrm{~m}^{3}$ and $4348 \mathrm{~m}^{3}$ of storm runoff with peak discharges of $0.886 \mathrm{~m}^{3} / \mathrm{s}$ and $1.367 \mathrm{~m}^{3} / \mathrm{s}$, respectively. To accommodate or dose for peak discharges, 234 and 360, 706B PAM floc blocks would be required, which seems infeasible. Average inflow rates were calculated and plotted on Figure 7 for the 2-year and 10-year, 24-h design storms; and would require 10 and 15, 706B PAM floc blocks, respectively. For both the 2-year and 10-year, 24-h design storms, there are about $21 \mathrm{~h}$ or $87.1 \%$ of the runoff hydrograph having discharges less than the corresponding average inflow rates, respectively, which account for about $32.4 \%$ of the total runoff volume. Figure 7 shows that it is difficult and challenging to dose stormwater runoff with the exact amount of PAM floc blocks for inflows from all rainfall events that a study area could experience during the design life because rainfall is a stochastic variable.

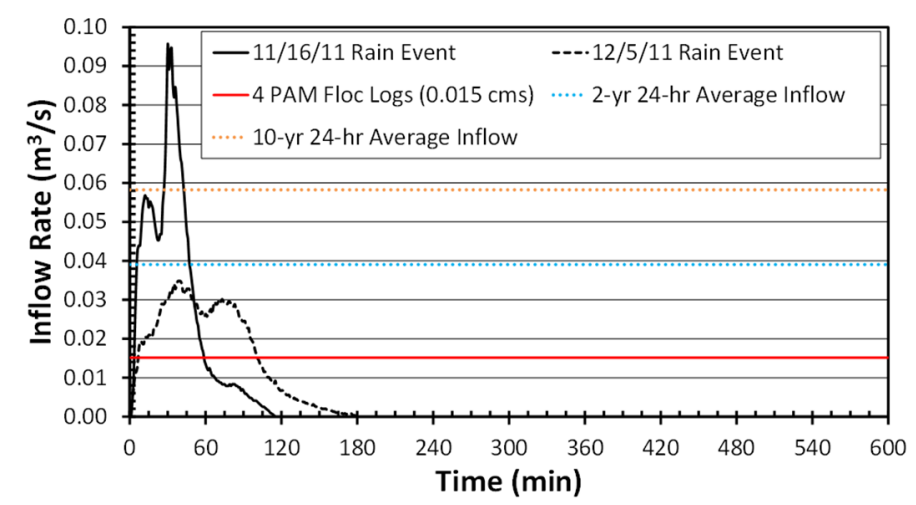

Figure 7. Cont. 


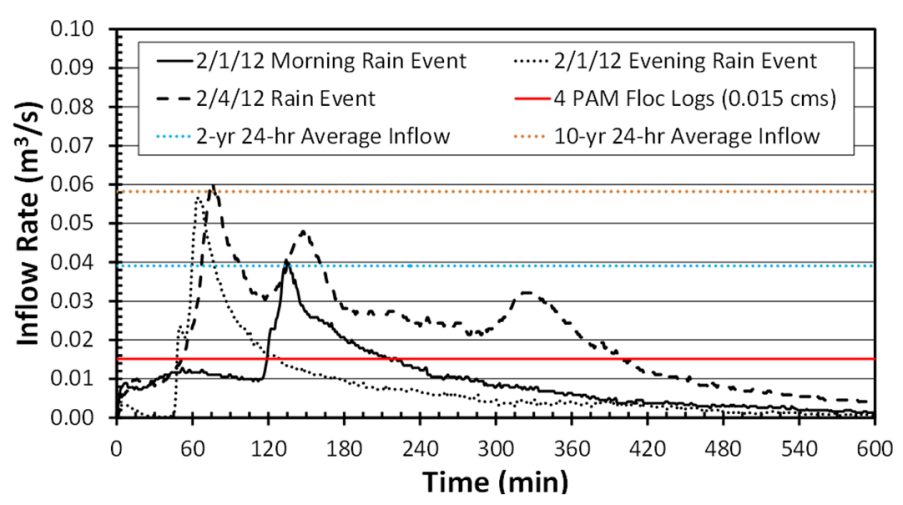

Figure 7. Observed inflow hydrographs for several rainfall events during the Phase I (top) and Phase II (bottom) data collection including effective flow rate using four floc blocks

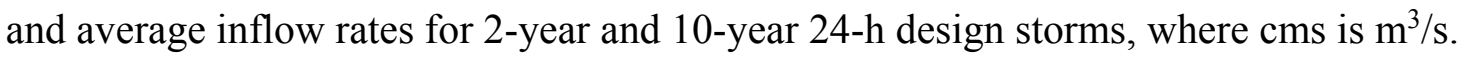

\section{Summary and Conclusions}

A field-scale data collection plan to monitor and evaluate sediment basin performance was developed and implemented using automatic stormwater samplers, flow modules, a rain gauge, and inflow weirs. As stormwater management and sediment control practices are employed to protect downstream water resources, the sediment basin on a construction project in Franklin County, AL was monitored from 15 November 2011 to 6 February 2012 over 16 rainfall events when inflow runoff was generated. Through completing the study, the following summary and conclusions have been developed:

- The sediment basin did effectively remove sediments during the early stages of construction when the basin's influent most likely contained a relatively large percentage of large-size sediment particles. The sediment basin removed $97.9 \%$ and $83.7 \%$ of sediments generated by rainfall events on 16 November 2011 and 5 December 2011, respectively.

- High-intensity rainfall impulses generated high turbidity inflows from the construction site, re-suspended previously settled sediments within the basin, and suddenly increased in-basin turbidity, which could be several times higher than turbidity of water already in the basin.

- The lessons learned and the challenges of the field data collection to evaluate the performance of the sediment basin were listed and summarized, which will benefit the professional community for planning future studies on sediment basin monitoring efforts.

Using $251.9 \mathrm{~m}^{3} /$ ha design standard, the basin associated with 3.73 ha watershed would provide $938.9 \mathrm{~m}^{3}$ of storage, which would be sufficient to hold the observed runoff volumes produced by rain events during both Phase I and Phase II data collection efforts. Further research is necessary to determine whether the basin should be designed and sized using a 2-year 24-h storm. It is recommended that the height of the baffles match or exceed the full depth of the sediment basin and not be installed below the minimum elevation of the emergency spillway, preventing stormwater from overtopping them and creating a fully mixed condition. Further research is necessary to determine where and how PAM floc blocks can be effectively and practically introduced in the inflow channel system to achieve adequate dosage, agitation, and contact time. 


\section{Acknowledgment}

This paper is based on a study sponsored by ALDOT, the authors gratefully acknowledge this financial support. The findings, opinions, and conclusions expressed in this paper are those of the authors and do not necessarily reflect the view of the sponsor. The authors thank four anonymous reviewers and Michael A. Perez at Auburn University who provided constructive comments and suggestions that helped authors to improve the quality of the manuscript.

\section{Author Contributions}

Xing Fang and Wesley Zech analyzed the data and contributed significantly in writing and revising the manuscript. Christopher Logan contributed significantly in collecting the field data for the study, performed initial data analysis, and authored portions of the manuscript.

\section{Conflicts of Interest}

The authors declare no conflict of interest.

\section{References}

1. United States Environmental Protection Agency (USEPA). Stormwater Phase II Finale Rule-Construction Site Runoff Control Measure; EPA Federal Register: Washington, DC, USA, 2005; Volume 833-F-00-008.

2. United States Environmental Protection Agency (USEPA). Effluent Limitations Guidelines and Standards for the Construction and Development Point Source Category; USEPA: Washington, DC, USA, 2013.

3. National Pollutant Discharge Elimination System Permit-General Perimt. Available online: http://adem.alabama.gov/programs/water/waterforms/ALR10CGP.pdf (accessed on 29 June 2015).

4. United States Environmental Protection Agency (USEPA). Development Document for Final Effluent Guidelines and Standards for the Construction \& Development Category; USEPA, Office of Water: Washington, DC, USA, 2009.

5. Alabama Soil and Water Conservation Committee (ASWCC). Alabama Handbook for Erosion Control, Sediment Control, and Stormwater Management on Construction Site and Urban Areas; ASWCC: Montgomery, AL, USA, 2006; Volume 1, p. 374.

6. Jarrett, A.R. Design of perforated risers to control dewatering of sedimentation basins. Appl. Eng. Agric. 1993, 9, 37-42.

7. Alabama Soil and Water Conservation Committee (ASWCC). Alabama Handbook for Erosion Control, Sediment Control, and Stormwater Management on Construction Site and Urban Areas; ASWCC: Montgomery, AL, USA, 2009.

8. Millen, J.A.; Jarrett, A.R.; Faircloth, J.W. Experimental evaluation of sedimentation basin performance for alternative dewatering systems. Trans. Am. Soc. Agric. Eng. 1997, 40, 1087-1095.

9. Rauhofer, J.; Jarrett, A.R.; Shannon, R.D. Effectiveness of sedimentation basins that do not totally impound a runoff event. Trans. Am. Soc. Agric. Eng. 2001, 44, 813-818. 
10. Bidelspach, D.A.; Jarrett, A.R.; Vaughan, B.T. Influence of increasing the delay time between the inflow and outflow hydrographs of a sediment basin. Trans. Am. Soc. Agric. Eng. 2004, 47, 439-444.

11. Thaxton, C.S.; Calantoni, J.; McLaughlin, R.A. Hydrodynamic assessment of various types of baffles in a sediment retention pond. Trans. Am. Soc. Agric. Eng. 2004, 47, 741-749.

12. Thaxton, C.S.; McLaughlin, R.A. Sediment capture effectiveness of various baffle types in a sediment retention pond. Trans. Am. Soc. Agric. Eng. 2005, 48, 1795-1802.

13. McCaleb, M.M.; McLaughlin, R.A. Sediment trapping by five different sediment detention devices on construction sites. Trans. ASABE 2008, 51, 1613-1621.

14. Kang, J.; King, S.E.; McLaughlin, R.A. Impacts of flocculation on sediment basin performance and design. Trans. Am. Soc. Agric. Eng. 2014, 57, 1099-1107.

15. North Carolina Department of Transportation (NCDOT). Sediment traps and barriers. In North Carolina Erosion and Sediment Control Planning and Design Manual; NCDOT: Raleigh, NC, USA, 2013; p. 58.

16. Hossain, M.A.; Alam, M.; Yonge, D.R.; Dutta, P. Efficiency and flow regime of a highway stormwater detention pond in washington, USA. Water Air Soil Pollut. 2005, 164, 79-89.

17. McLaughlin, R.A.; Hayes, S.A.; Clinton, D.L.; McCaleb, M.M.; Jennings, G.D. Water quality improvements using modified sediment control systems on construction sites. Trans. ASABE 2009, 52, 1859-1867.

18. Bidelspach, D.A.; Jarrett, A.R. Electro-Mechanical outlet flow control device delays sediment basin dewatering. Appl. Eng. Agric. 2004, 20, 759-763.

19. Bhardwaj, A.K.; McLaughlin, R.A. Simple polyacrylamide dosing systems for turbidity reduction in stilling basins. Trans. ASABE 2008, 51, 1653-1662.

20. Haan, C.T.; Barfield, B.J.; Hayes, J.C. Design Hydrology and Sedimentology for Small Catchments; Academic Press: New York, NY, USA, 1994.

21. Bentzen, T.R.; Larsen, T.; Rasmussen, M.R. Predictions of resuspension of highway detention pond deposits in interrain event periods due to wind-induced currents and waves. J. Environ. Eng. 2009, 135, 1286-1293.

22. Barfield, B.J.; Clar, M. Development of New Design Criteria for Sediment Traps and Basins; Maryland Resource Administration: Annapolis, MD, USA, 1985.

23. Line, D.E.; White, N.M. Efficiencies of temporary sediment traps on two North Carolina construction sites. Trans. Am. Soc. Agric. Eng. 2001, 44, 1207-1215.

24. Comings, K.J.; Booth, D.B.; Horner, R.R. Storm water pollutant removal by two wet ponds in bellevue, Washington. J. Environ. Eng. 2000, 126, 321-330.

25. Zhou, S.; McCorquodale, J.A. Modeling of rectangular settling tanks. J. Hydraul. Eng. 1992, 118, 1391-1405.

26. Pitt, R.E.; Clark, S.E.; Lake, D.W. Construction Site Erosion and Sediment Controls: Planning, Design, and Performance; DEStech Publications, Inc.: Lancaster, PA, USA, 2007; p. 381.

27. Madaras, J.S.; Jarrett, A.R. Spatial and temporal distribution of sediment concentration and particle size distribution in a field scale sedimentation basin. Trans. Am. Soc. Agric. Eng. 2000, 43, 897-902.

28. Bhardwaj, A.K.; McLaughlin, R.A.; Babcock, D.L. Energy dissipation and chemical treatment to improve stilling basin performance. Trans. ASABE 2008, 51, 1645-1652. 
29. Zech, W.C.; Logan, C.P.; Fang, X. State-of-the-practice: Evaluation of sediment basin design, construction, maintenance, and inspection procedures. ASCE Pract. Period. Struct. Des. Constr. 2014, 19, doi:10.1061/(ASCE)SC.1943-5576.0000172.

30. Hach Company. Determining the Relationship between Turbidity and Total Suspended Solids. In Hach Method 8366 Analytical Procedures; Hach Company: Loveland, CO, USA, 2011.

31. American Society of Testing and Materials (ASTM). ASTM d6913-04(2009)e1: Standard Test Methods for Particle-size Distribution (Gradation) of Soils Using Sieve Analysis; American Society of Testing and Materials (ASTM) International: West Conshohocken, PA, USA, 2009.

32. North Carolina Department of Transportation (NCDOT). Sediment traps and barriers. In Practice Standards and Specifications; NCDOT: Raleigh, NC, USA, 2006.

33. Logan, C.P. Assessing Performance Characteristics of Sediment Basins Constructed in Franklin County of Alabama. Master's Thesis, Auburn University, Auburn, AL, USA, 2012.

34. Wanielista, M.P.; Yousef, Y.A. Stormwater Management; John Wiley \& Sons, Inc.: New York, NY, USA, 1993.

35. U.S. Department of Agriculture (USDA). Soil Survey of Porter County, Indiana; USDA Soil Conservation Service: Washington, DC, USA, 1981.

36. Viessman, W.; Lewis, G.L. Introduction to Hydrology, 5th ed.; Pearson Education: Upper Saddle River, NJ, USA, 2003; p. 612.

37. U.S. Environmental Protection Agency (USEPA). National Pollutant Discharge Elimination System General Permit for Discharges from Construction Activities; USEPA: Washington, DC, USA, 2012.

(C) 2015 by the authors; licensee MDPI, Basel, Switzerland. This article is an open access article distributed under the terms and conditions of the Creative Commons Attribution license (http://creativecommons.org/licenses/by/4.0/). 